\title{
Journal of Negative Results in BioMedicine
}

Research

\section{Capsaicin- resistant arterial baroreceptors Patrick J Reynolds'1, Wei Fan ${ }^{2}$ and Michael C Andresen*1}

Address: ${ }^{1}$ Department of Physiology and Pharmacology, Oregon Health \& Science University, Portland, Oregon 97239-3098, USA and ${ }^{2}$ Vollum Institute, Oregon Health \& Science University, Portland, Oregon 97239-3098, USA

Email: Patrick J Reynolds - pjreynolds@msn.com; Wei Fan - fanw@ohsu.edu; Michael C Andresen* - andresen.ohsu@gmail.com

* Corresponding author

Published: 18 May 2006

Journal of Negative Results in BioMedicine 2006, 5:6 doi:10.1 I86/I477-575I-5-6

This article is available from: http://www.jnrbm.com/content/5/I/6

(c) 2006 Reynolds et al; licensee BioMed Central Ltd.

This is an Open Access article distributed under the terms of the Creative Commons Attribution License (http://creativecommons.org/licenses/by/2.0), which permits unrestricted use, distribution, and reproduction in any medium, provided the original work is properly cited.
Received: 08 April 2006

Accepted: 18 May 2006

\begin{abstract}
Background: Aortic baroreceptors (BRs) comprise a class of cranial afferents arising from major arteries closest to the heart whose axons form the aortic depressor nerve. BRs are mechanoreceptors that are largely devoted to cardiovascular autonomic reflexes. Such cranial afferents have either lightly myelinated (A-type) or non-myelinated (C-type) axons and share remarkable cellular similarities to spinal primary afferent neurons. Our goal was to test whether vanilloid receptor (TRPVI) agonists, capsaicin (CAP) and resiniferatoxin (RTX), altered the pressure-discharge properties of peripheral aortic BRs.
\end{abstract}

Results: Periaxonal application of I $\mu$ M CAP decreased the amplitude of the C-wave in the compound action potential conducting at $<1 \mathrm{~m} / \mathrm{sec}$ along the aortic depressor nerve. $10 \mu M$ CAP eliminated the $C$-wave while leaving intact the $A$-wave conducting in the $A-\delta$ range $(<12 \mathrm{~m} / \mathrm{sec})$. These whole nerve results suggest that TRPVI receptors are expressed along the axons of $C$ - but not A-conducting BR axons. In an aortic arch - aortic nerve preparation, intralumenal perfusion with I $\mu M$ CAP had no effect on the pressure-discharge relations of regularly discharging, single fiber BRs (A-type) - including the pressure threshold, sensitivity, frequency at threshold, or maximum discharge frequency $(n=8, p>0.50)$ but completely inhibited discharge of an irregularly discharging BR (C-type). CAP at high concentrations (10-100 $\mu \mathrm{M})$ depressed BR sensitivity in regularly discharging BRs, an effect attributed to non-specific actions. RTX $(\leq 10 \mu \mathrm{M})$ did not affect the discharge properties of regularly discharging BRs $(n=7, p>0.18)$. A CAP-sensitive BR had significantly lower discharge regularity expressed as the coefficient of variation than the CAPresistant fibers $(p<0.002)$.

Conclusion: We conclude that functional TRPVI channels are present in C-type but not A-type (A- $\delta$ ) myelinated aortic arch BRs. CAP has nonspecific inhibitory actions that are unlikely to be related to TRVI binding since such effects were absent with the highly specific TRPVI agonist RTX. Thus, CAP must be used with caution at very high concentrations.

\section{Background}

Sensory information from visceral organs enters the central nervous system via separate pools of primary afferents that synapse at either the spinal cord or the brain stem
$[1,2]$. Cranial primary afferents that synapse first within the brain stem have cell bodies in the nodose ganglia (NG) and share many general morphological, cellular and molecular properties with the somatic and visceral sen- 
A

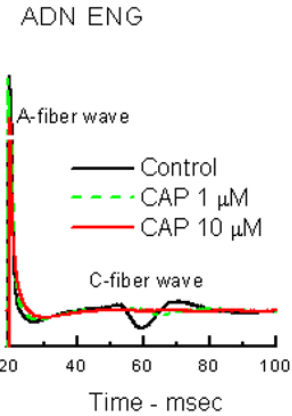

B

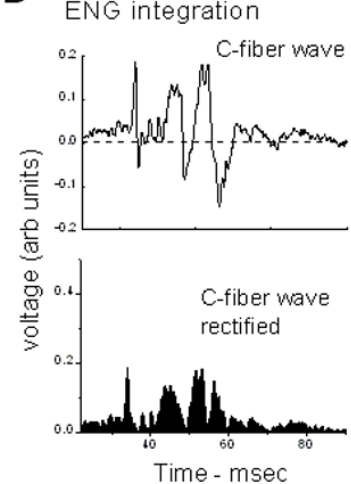

\section{Figure I}

Capsaicin depressed the $\mathrm{C}$-wave recorded from the whole nerve trunk of the aortic depressor nerve (ADN). The ADN electroneurogram (ENG) had an early arriving $A$-wave and a late broad, $C$-wave (panel $A$ ). This representative $A D N$ was estimated to be $21 \mathrm{~mm}$ in length. Application of a pledget soaked in saline (Control), I $\mu$ M CAP (green, broken) and then $10 \mu \mathrm{M}$ CAP (red) for ten min at each condition resulted in progressive depression and then elimination of the slow conducting $(0.5 \mathrm{~m} / \mathrm{sec}) \mathrm{C}$-wave while the fast conducting, Awave was preserved. Note that the $y$-axis is broken to better display the $\mathrm{C}$-wave. Amplitude units are arbitrary since the degree of electrical isolation varied from nerve to nerve and was affected by saline shunting and the length of free nerve ending. For semi-quantitative comparisons across nerves, segments of the ENG were full wave rectified and digitally integrated to represent the amplitude of the entire wave (panel B, lower).

sory neurons that send information to the spinal cord and whose cell bodies lie in the spinal dorsal root ganglia (DRG) [3]. On the basis of the structure of their peripheral axons and conduction velocities, spinal and cranial sensory neurons are divided into two broad subdivisions as myelinated (A-fiber) or unmyelinated (C-fiber) phenotypes [4]. A key membrane channel protein associated with C-type sensory neurons is the vanilloid receptor TRPV1 (or VR1) [5], although lightly myelinated, A- $\delta$ spinal sensory neurons may also express TRPV1 [6-8]. Surveys of mRNA suggest that TRPV1 is expressed in over $80 \%$ of NG as well as DRG neurons [9]. The functional significance of TRPV1 in NG neurons is generally unclear, although in gastrointestinal vagal afferents is associated with gastric mucosal acid exposure [10].

Arterial baroreceptors (BRs) are a specific group of cranial afferent neurons that have structurally primitive mechanically sensitive endings within the adventitial layer of large central arteries such as the aortic arch $[11,12]$. Aortic BRs with A- and C-type axons have distinctive pressure-dis-

charge properties [13]. The rat aortic depressor nerve can be isolated in vitro in an aortic arch preparation and highly stable recordings made from single fiber aortic arch BRs[14]. Here, our goal was to test under highly controlled conditions in vitro whether the compound action potentials and pressure-discharge relations of aortic BRs were affected by TRPV1 activation. Using two selective ligands, CAP and resiniferatoxin (RTX), the data suggest that myelinated, regularly discharging A-type BRs are highly CAP-resistant but that CAP must be used with caution at very high concentrations even with A-type BRs.

\section{Results}

CAP blocks C-fiber volley of aortic depressor nerve trunk The nerve trunk of the aortic depressor nerve (ADN) runs separately as a distinct axon bundle from the sensory arbors of the individual BRs at the aortic arch until merging with the vagal trunk near the NG. Cutting both ends of the ADN (peripheral and aortic arch ends) and stripping them of their outer sheath provided sufficient length of nerve to stimulate and record the conducted whole nerve compound action potential [15]. At the lowest stimulation intensities, shocks to the ADN elicited an early arriving, very short duration compound action potential. Increasing the intensity of the electrical stimulus shock added a broad, slowly conducted, compound spike following the sharp, early spike (Figure 1). Supramaximal stimulation intensities activated these two, distinct volleys with the early arriving spike corresponding to calculated conduction velocities of between 8 and $12 \mathrm{~m} / \mathrm{sec}(\mathrm{n}=6)$ that were within the $A \delta$-fiber range of conduction (Figure 1A). The late arriving and often more complex volley (Figure $1 \mathrm{~B}$ ) had lower amplitude and much longer duration often 20-40 msec - and the leading edge of the late wave corresponded to a calculated conduction velocity of not greater than $1 \mathrm{~m} / \mathrm{sec}$ in all cases $(\mathrm{n}=6)$. Such evoked responses were stable in control experiments over periods of $>30 \mathrm{~min}$. Addition of $1 \mu \mathrm{M}$ CAP (Figure 1A) at a point along the ADN trunk between the stimulating and the recording electrodes substantially reduced the C-fiber volley amplitude and delayed its arrival in time after $15 \mathrm{~min}$ exposure. To facilitate comparison, ENG signals were full wave rectified and then integrated to express complex waveform magnitudes (Figure 1B). On average $(n=4), 1$ $\mu \mathrm{M}$ CAP did not significantly alter the A-fiber volley integral $(0.68 \pm 0.17$ vs. $0.88 \pm 0.18 ; p>0.05)$, but significantly depressed the C-fiber volley $(1.38 \pm 0.16$ vs. $0.51 \pm$ $0.16, \mathrm{p}<0.02)$. Thus, aortic C-fiber BR axons in the ADN trunk are CAP-sensitive and the A-fiber axons are CAPresistant.

\section{Single fiber baroreceptor responses to CAP}

In order to test pressure activation of single fiber aortic BRs under highly controlled conditions, we isolated the $\mathrm{ADN}$ together with the aortic arch in an in vitro prepara- 

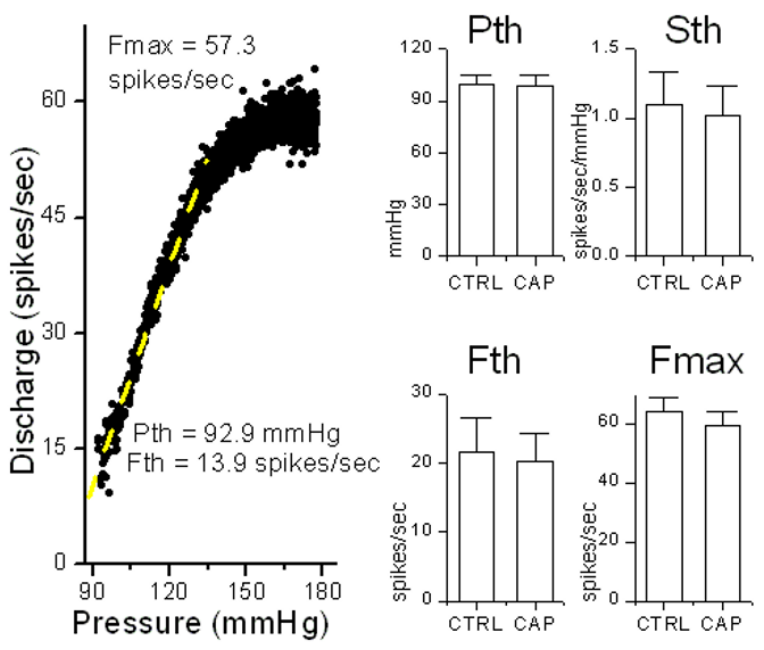

\section{Figure 2}

Capsaicin-resistant baroreceptors. Capsaicin effects on the pressure-discharge relations of regularly discharging, single-fiber, aortic BRs were assessed by comparing four key discharge parameters. Pressure threshold (Pth) and threshold frequency (Fth) were calculated as the average pressure and frequency (respectively) for the first 10 discharge points. The slope sensitivity (Sth) was based on a least squares, linear regression fit of the discharge points over the initial 20-40 $\mathrm{mmHg}$ of the relation (white dashed line). The maximum discharge (Fmax) averaged the discharge frequency sampled from the highest $20 \mathrm{mmHg}$ for that unit - generally >200 points. The classification as regularly discharging was based on a moderate $(<\%)$ coefficient of variation (COV) of discharge, high Fmax $(>50 \mathrm{~Hz})$ and high slope-sensitivity $(>0.5$ spikes/sec/mmHg) - all characteristic of A-fiber BRs. I $\mu \mathrm{M}$ CAP for 15 min failed to alter the pressure-discharge response of regularly discharging $B R s(n=10)$ or their mean discharge parameters. The COV was calculated using this same sample and for this BR was $2.94 \%$. Linear regression fit $(\mathrm{Y}=\mathrm{A}+\mathrm{B} * \mathrm{X})$ yielded $\mathrm{A}=-75.0 \pm 0.9, \mathrm{~B}=0.95 \pm 0.0 \mathrm{I}, \mathrm{R}=$ $0.99 \pm \mathrm{I} .68, \mathrm{n}=470$ points, $\mathrm{P}$-value $<0.000 \mathrm{I}$. Averages $( \pm$ SEM) of these derived parameters for Pth, Sth, Fth and Fmax.

tion[14,16,17]. Split fibers containing single active BR units were dissected from the nerve trunk and subjected to slow ramp increases in aortic arch pressure while recording the nerve discharge. The most common pressure-discharge relation for single fiber BRs showed a very tight band of highly regular discharge (Figure 2). Such BRs had relatively low absolute threshold values (Pth), a sharp jump in frequency at threshold from zero to 15-20 spikes/sec (Fth) and maximum discharge rates of 50-60 $\mathrm{Hz}$ (Fmax). The calculated coefficient of variation (COV) for regularly discharging BRs was $3.2+/-1.4 \%, \mathrm{n}=9$. These discharge characteristics are typical of myelinated aortic BRs $[13,18]$. Mean perfusion pressure was held at
$80 \mathrm{mmHg}$ to control for acute resetting [19] and under these conditions the pressure-discharge relations were superimposable over the full control periods of at least 15 min. Perfusion of the lumen of the aortic arch with $1 \mu \mathrm{M}$ CAP did not alter any aspect of the pressure-discharge properties of such regularly discharging BRs even after 15 min (Figure 2$)$. On average $(n=10)$, the discharge properties of regularly discharging BRs were unaltered by $1 \mu \mathrm{M}$ CAP (Figure 2). CAP did not alter Pth $(\mathrm{p}=0.79)$, Sth $(\mathrm{p}=$ $0.80)$, Fth $(\mathrm{p}=0.84)$ or Fmax $(\mathrm{p}=0.57)$. Thus, at concentrations of CAP that interrupted C-wave axonal transmission in the ADN trunk, the responses of regularly discharging BRs to pressure were unaffected. This $1 \mu \mathrm{M}$ concentration of CAP is close to the $K_{D}(2 \mu \mathrm{M})$ reported for DRG neurons[20].

Routine testing of active single BR fibers used ramped pressure tests to $160-180 \mathrm{mmHg}$ in an attempt to record C-fiber BRs. C-fiber BRs generally require relatively higher pressures for activation than for regularly discharging Atype BRs $[13,18]$. One single fiber BR had a relatively high Pth (106 $\mathrm{mmHg}$ ) and irregular discharge under control conditions (Figure 3). Discharge began at near zero and only gradually increased as pressure ramped higher. The irregular discharge produced a scattered band of points as pressure increased. At the upper levels of firing, the broad irregularity produced a COV of $9.9 \%$ - over three fold greater than the regular discharge group and a value highly unlikely to belong to the regular discharging $\mathrm{BR}$ group $(\mathrm{p}<0.02)$. The low and irregular discharge rate plus the low value for the slope sensitivity (Sth) are characteristic of rat C-type BRs $[13,18]$. Addition of $1 \mu \mathrm{M}$ CAP to the perfusate (Figure 3 ) rapidly depressed the pressure discharge relation beginning at $5 \mathrm{~min}$ exposure (Figure 3). The BR failed to sustain discharge at high pressures but discharge near threshold was generally similar to control. By 10 min in CAP, discharge from this BR was no longer sustained above $125 \mathrm{mmHg}$. At $15 \mathrm{~min}$ in $1 \mu \mathrm{M}$ CAP, the BR was nearly inexcitable and only fired a scattering of action potentials to aortic arch pressures above its control threshold level (Figure 3). This inhibition of discharge was partially reversed following $30 \mathrm{~min}$ of CAP-free wash. Thus, CAP eliminated the response to pressure of this irregularly discharging $\mathrm{BR}$.

\section{Capsaicin but not RTX non-specific depresses BR discharge at high concentrations}

Reports suggest that CAP has additional, non-specific effects at concentrations that are well beyond saturation of specific binding sites at TRPV1 [20]. Given the high binding specificity of these agonists for TRPV1 [20], we considered concentrations 100 fold greater than the known receptor $\mathrm{Kd}$ as potentially nonspecific. We tested much higher concentrations of CAP in otherwise CAP-resistant, A-type BRs (\#10 $10 \mathrm{M}, \mathrm{n}=6$ ). At concentrations $>10 \mu \mathrm{M}$, 
CAP-sensitive BR

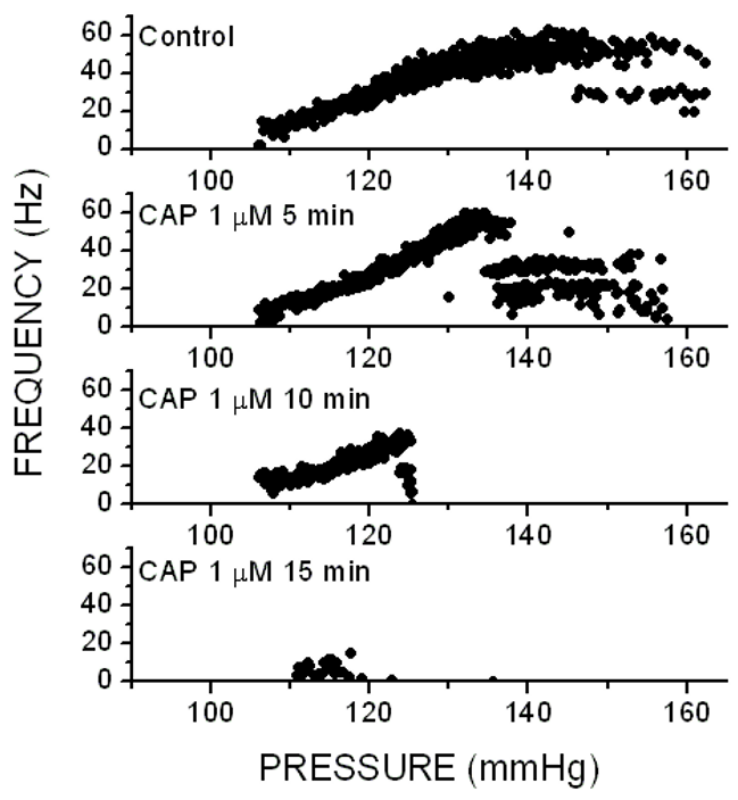

Figure 3

Capsaicin-sensitive baroreceptor. Capsaicin (I $\mu \mathrm{M})$ depressed the pressure-discharge response of an irregular aortic BR.

The discharge properties including high coefficient of variation (COV = 9.9) of discharge, low discharge rate (maximum of $40 \mathrm{~Hz}$ ) and low slope-sensitivity - all characteristic of Cfiber BRs. Pressure was ramped from $40-160 \mathrm{mmHg}$ at a rate of $\mathrm{I} \mathrm{mmHg} / \mathrm{sec}$. CAP progressively interrupted discharge with intermittent drops in discharge rates to half or less the prevailing rate (points at high pressures falling below the general trend). At 10 min and beyond, the BR failed to respond to suprathreshold pressures and at 15 min the relation was completely blocked. The loss of individual instantaneous frequency points by discrete increments (integer reciprocals, e.g 1/2. I/3, etc.) indicates likely conduction block.

CAP modified the pressure-discharge relations in a distinctly different manner than observed in the irregularly discharging CAP-sensitive BR (Figure 3). $100 \mu \mathrm{M}$ CAP substantially increased the Pth and depressed the slope and maximum discharge of pressure discharge relations of regularly discharging BRs (Figure 4). In half the neurons tested, these effects reversed poorly with persistent depression lasting through extended periods of perfusion in CAP-free solution (>30 min).

The ultrapotent RTX may be effective at $>100 x$ lower concentrations than CAP[21]. Here, we tested RTX actions on pressure-evoked BR discharge. RTX at concentrations from $1 \mathrm{nM}$ to $10 \mu \mathrm{M}$ had no significant effects on pressure-dis- charge relations of regularly discharging, A-type single unit BRs. On average $(\mathrm{n}=7$, Figure 5), $1 \mu \mathrm{M}$ RTX did not alter Pth, Sth, Fth, or Fmax ( $p>0.18, \mathrm{n}=7)$. In one BR, RTX concentration was increased to $10 \mu \mathrm{M}$ RTX (Figure 5, left), a level that is more than 1000 times higher than the expected ED50 without "nonspecific" effects on pressuredischarge relations. This finding contrasts with the frank depression of A-type BR pressure-discharge relations found with high CAP concentrations (Figure 4).

\section{Discussion}

The rat $\mathrm{ADN}$ is a unique peripheral nerve trunk since it contains only aortic BR afferent axons [22-24]. This thin ADN nerve bundle ( $\sim 100 \mu \mathrm{m}$ diameter) consists of up to $80 \%$ C-fibers of the total axon population $[11,25,26]$ without the efferent axons found in the peripheral vagus or somatic nerve trunks. This anatomical feature means that, experimentally, ENGs evoked by electrical stimulation are responses to a relatively uniform modality of primary visceral afferents - in this case BRs - and should not be influenced by contributions from antidromically activated efferent (non-sensory) axons of similar conduction velocity that can be a complication in recordings from a mixed (afferent-efferent) nerve trunk. The close correspondence in our CAP results between the population

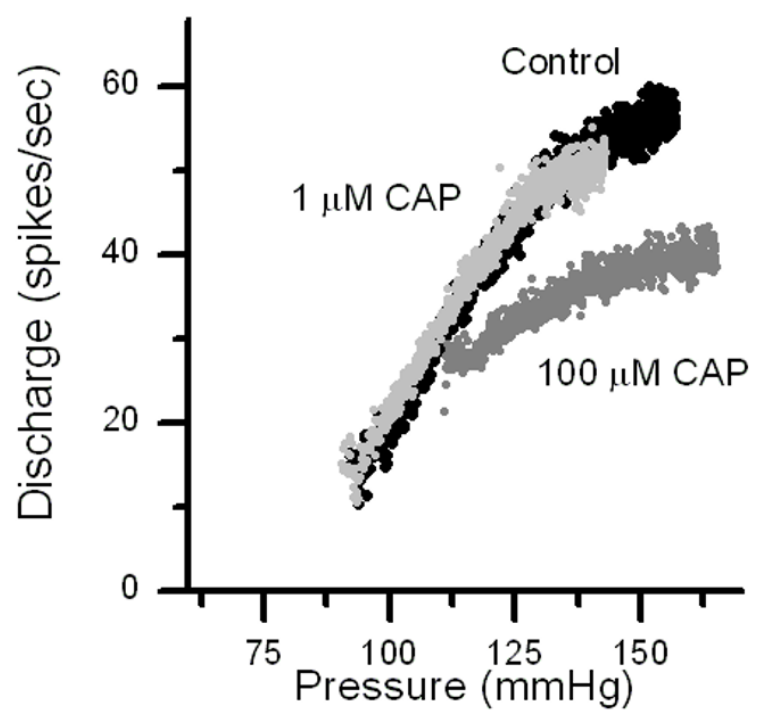

Figure 4

Non-specific actions of CAP on a capsaicin-resistant BR. I $\mu M$ CAP for 15 min (light gray points) failed to alter the pressure-discharge response of this regularly discharging $B R$ (control, black points). Raising CAP to $100 \mu \mathrm{M}$ depressed the slope of the discharge relation at I5 min exposure (dark gray points). 

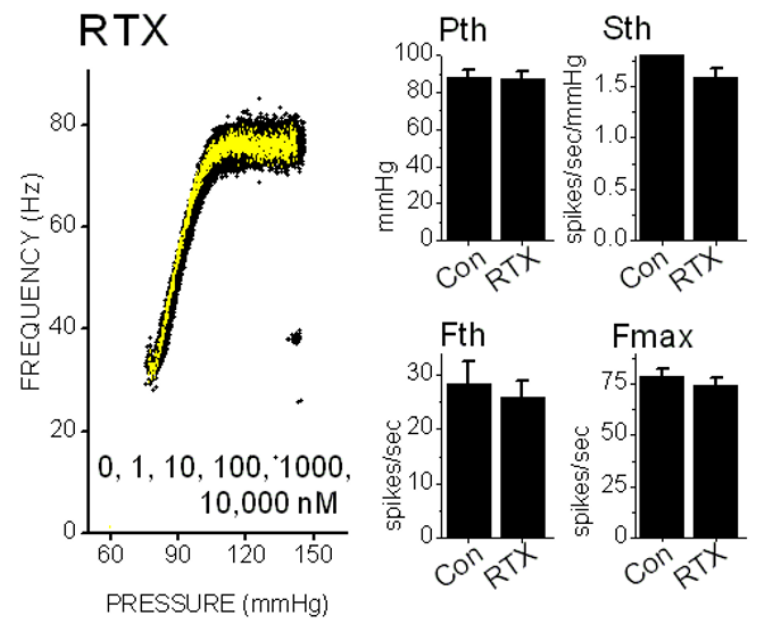

\section{Figure 5}

Resinferotoxin (RTX) did not alter the pressure-discharge relations of regularly discharging, CAP-resistant BRs. On the left, the pressure-discharge relations for a representative, regularly discharging $\mathrm{BR}(\mathrm{COV}=1.9 \%, \mathrm{n}=677$ points) that was exposed to RTX increasing concentrations ( $1,10,100$, $1000,10,000 \mathrm{nM}$ ) for $15 \mathrm{~min}$ each. The five pressure-discharge relations during RTX closely overlaid the original control relation (left panel). Instantaneous discharge values during 10,000 nM are colored yellow and all other datasets are black. The relationships completely overlapped. Average values for the discharge parameters (histograms on right) for seven regularly discharging BRs before and after 10,000 nM RTX are plotted. Pressure threshold (Pth), threshold frequency (Fth), slope sensitivity (Sth) and the maximum discharge frequency (Fmax) are displayed. Thus, unlike CAP, very high concentrations of RTX did not produce nonspecific effects on BR discharge.

ENG responses and our single fiber BR studies is consistent with this homogeneity. Our studies suggest two important findings about these cranial visceral afferents and their expression of TRPV1. First, aortic BRs possess CAP-resistant and CAP-sensitive peripheral nerve endings and the site of action is presumably close to or within the mechanoreceptive fields at the aortic arch wall. Second, very high concentrations of CAP but not RTX $(>10 \mu \mathrm{M})$ have additional inhibitory actions on these neurons that are consistent with non-specific effects.

A-type BR fibers were strongly resistant to CAP actions, both along their peripheral axons as well as in the pressure transduction process at their peripheral endings at the aortic arch. The CAP resistant component of the whole nerve measurements during ADN conduction was within the A $\delta$ class of BR axons - simply designated A-type. Such A-type BRs are likely typical of a broad association for cranial vis- ceral afferent neurons with CAP sensitivity. It was recently reported that nodose neurons with A-fiber conduction velocities did not respond to somatic exposure to CAP whereas C-fiber neurons were CAP-sensitive [27]. In addition, afferent synaptic transmission was block to some neurons within the central nervous system to neurons within the nucleus of the solitary tract (NTS) $[27,28]$. Together, our present peripheral nerve studies together with nodose ganglion and NTS studies indicate that TRPV1 is expressed in C-type, primary visceral afferent neurons at their cell body membrane as well as at both their peripheral sensory endings and central synaptic terminals.

In the present studies, we successfully recorded from only one single fiber BR with the irregular discharge pattern consistent with an unmyelinated BR [29,30]. Axon length was insufficient to measure the conduction velocity, but nonetheless, pressure-discharge responses in this highly irregular BR were blocked by $1 \mu \mathrm{M}$ CAP - a finding consistent with $\mathrm{ADN}$ whole nerve recordings and previous studies of rat ADN C-fiber BRs [29-31]. Like other BR modulating agents, lumenal perfusion with CAP rapidly influenced BR discharge properties despite the location of the BR endings within the adventitia [14,16]. Despite these limitations of the single fiber BR recordings, the ADN ENG results bolster the association of C-type BRs with CAP sensitivity and A-type BRs with CAP resistance consistent with other studies [27].

CAP has long been reported to have "non-specific" actions on neurons and other cell types that are not likely to involve activation of TRPV1 [20]. Chronic toxicity is likely related to prolonged activation of TRPV1 that may lead to calcium overload [32] but it should be noted that these toxic actions require that the affected neuron express TRPV1. In our case of "non-specific" actions, we presume that A-type BRs lack TRPV1 expression but nonetheless have discharge depressed by high concentrations of CAP that is, a TRPV1-independent action of CAP. Concentrations of substances delivered to the aortic lumen appear to faithfully reach the BR endings at the expected concentrations [14]. The concentration-response profile for our pledget application of CAP applied to the axon trunk suggests that this method of delivery may be highly inefficient and concentrations at the site of action may be much lower than applied concentrations [15]. Thus, $10 \mu \mathrm{M}$ CAP blocked C-fiber conduction in the ADN within $10 \mathrm{~min}$ but appeared to be specific in that A-fibers were not blocked [33]. However, $1 \mu \mathrm{M}$ CAP show similar C-selective axonal block but required $30 \mathrm{~min}$ in some ADNs.

For single fiber BR discharge, the qualitative pattern of the blockade by CAP was similar to other highly specific agents that modulate BR transduction [14,16,34,35]. In 
the CAP-sensitive BR, the upper limits of discharge frequency changed substantially during CAP. The relations did not shift along the pressure axis as is found for sodium channel blockade with TTX in BRs $[14,16]$. Less selective agents than TTX that are known to act at both sodium and potassium channels such as local anesthetics $[14,16,36]$. Likewise, changes in extracellular ion gradients[16,37] change threshold parameters as well as slope sensitivities of BRs. Thus, in the case of the CAP-sensitive BR responses, the transduction of pressure appeared to remain intact since the threshold and slope sensitivity to pressure were constant until final block developed. However in A-type BRs, the high concentrations of CAP produced multiple, global changes in the pressure-discharge relations, changes that are consistent with multiple targets of action. Interestingly, RTX, a high affinity ligand for VR1, did alter regularly discharging BRs even at higher relative concentrations [20]. The broader impact on BR discharge characteristics at very high concentrations conceivably could be a consequence CAP perturbation of lipid-protein interactions such as ion channels[20]. Thus, non-specific actions of CAP may depress a range of ion channels indirectly in A-type BRs lacking TRPV1 expression.

Our whole-nerve ADN recordings provide conduction velocity information on the population of $A D N$ BR primary afferents. In this respect, no BR in our single fiber BR studies should have a conduction velocity beyond $12 \mathrm{~m} /$ $\mathrm{sec}-\mathrm{a}$ value that corresponds to the lightly myelinated $\mathrm{A} \delta$ class of fibers[4,38]. The broad ENG profile of the C-fiber volley suggests that $\mathrm{ADN}$ non-myelinated fibers range in conduction velocity from $1 \mathrm{~m} / \mathrm{sec}$ to as low as $0.2 \mathrm{~m} / \mathrm{sec}$. Within these limits, ADN BRs conduct within similar ranges of both the A $\delta$ and C-fiber nociceptive fibers of the DRG [39]. Presumably, BR neurons would be among the neurons expressing TRPV1 mRNA at the NG $[9,40]$. VR1 protein is present in the medial portions of the NTS in which BR sensory neurons have synaptic terminations $[41,42]$. CAP evoked somatic inward currents only in NG neurons recorded in slices with the with conduction velocities in the C-fiber range and A-fiber NG neurons were CAP-resistant[27]. Together, the evidence suggests that TRPV1 is present only in cranial visceral primary afferents with C-fiber axon type and that CAP-resistant BRs have A-type conducting axons and lack TRPV1 expression.

Overall, A-type aortic BR neurons appear devoid of functional TRPV1. C-type aortic BRs express TRPV1 in their peripheral axons and in their aortic arch terminations and appear to be part of a broader group of cranial visceral afferents that are known to be CAP-sensitive and centrally provide for respiratory and gastrointestinal as well as cardiovascular regulation $[43,44]$. Interestingly, activation of aortic BRs and the arterial baroreflex evoke anti-nociceptive responses in animals and in humans $[45,46]$. Ultimately, the role of TRPV1 is unclear in cranial visceral afferents but conceivably could contribute to surveillance of tissue damage [47].

\section{Conclusion}

We conclude that functional TRPV1 channels are not present in A- $\delta$ myelinated BRs at their aortic arch endings or peripheral axons. CAP, unlike the ultrapotent TRPV1 agonist RTX, had additional non-specific actions to inhibit discharge of pressure activated A-type aortic BRS at very high concentrations. Thus, CAP appears to have toxic actions at high concentrations that are independent of TRV1 expression and must be used with caution in experiments in which concentration is not well controlled.

\section{Methods}

All animal procedures were conducted with the approval of the Institutional Animal Care and Use Committee in accordance with the U.S. Public Health Service Policy on Humane Care and Use of Laboratory Animals (PHS Policy) and the National Institutes of Health Guide for the Care and Use of Laboratory Animals (NIH Guide). Experiments used adult male Sprague-Dawley rats (B \& K, Inc., Kent, Washington, 250-450 g).

\section{Isolation of the left aortic depressor nerve}

Rats were anesthetized with pentobarbital sodium (ip 35$50 \mathrm{mg} / \mathrm{kg}$ ). The methods of the fine dissection to isolate the left ADN as well as removing the ADN with the aortic arch intact have been described in detail previously[25]. Briefly, following a ventral midline incision in the neck, the trachea was intubated and connected to a ventilator. The chest was opened at the midline along the sternum and the chest wall retracted to expose the heart and aortic arch. From the NG to the aortic arch, the ADN was microdissected under 20-60x magnification of a stereomicroscope (Wild 6A, Heerbrugg, $\mathrm{CH}$ ). In whole nerve trunk experiments, the ADN was sectioned close to the aortic arch and near the NG recorded in situ [15] with distal nerve stimulation and recording of the evoked wholenerve, compound action potential through hook electrodes under oil. For recording single BR discharge from the in vitro ADN aortic arch preparation, the aortic arch was cannulated and removed with the ADN for mounting in a perfusion-recording chamber.

\section{Compound action potentials in ADN}

Isolation of sufficient lengths of $\mathrm{ADN}$ in order to measure conduction velocity of the fastest conducting fibers is difficult [15]. Here, bipolar electrode pairs (Teflon-coated PtIr wires) were placed on both the rostral and caudal cut ends of the ADN trunk. The path distance for conduction between them was measured with an ocular micrometer 
of the stereomicroscope at $36 \times$ magnification. The nerve and electrodes were then covered with a mixture of petroleum jelly and warm mineral oil for isolation. Electrical stimuli were delivered via one electrode pair and the other pair recorded evoked compound action potentials. The stimulating electrodes were connected to a computer-controlled programmable stimulator (AMPI Master-8) through a stimulus isolation unit. CAP or vehicle was delivered to the axon bundle at an exposed region between the two sets of electrodes using small pieces of solution soaked cotton[15]. Threshold stimulus intensities were established in each preparation. Shocks were 0.1 msec in pulse duration. Supramaximal stimulus intensities consistently activated similar electroneurogram (ENG) waves in the ADN when the nerve was stimulated once each $30 \mathrm{sec}$. Compound action potentials were captured for analysis using either a digital oscilloscope (Hewlett-Packard 54645A, Agilent Technologies, Palo Alto, CA) or computer (Datawave Technologies, Longmont, CO). Components of the compound action potentials were compared before and after VR1 agonist treatment by full wave rectification followed by integration (Figure 1). These integrals measured the selected wave component over a $10 \mathrm{msec}$ interval centered on the A-wave and over a $50 \mathrm{msec}$ interval centered on the complex C-wave. The time of appearance within the ENG corresponded to the range of conduction velocities.

\section{In-vitro $B R$ pressure-discharge recording}

The aortic arch with attached ADN was placed within a temperature-regulated $\left(36-37^{\circ} \mathrm{C}\right)$ chamber to provide a stable controlled preparation in which highly reproducible pressure stimuli were delivered through the stainless steel cannulae of the perfusion system. The arch was continuously perfused $(3 \mathrm{ml} / \mathrm{min})$ with a physiological buffered salt solution (PBS). PBS contained the following in $\mathrm{mM}$ : $120 \mathrm{NaCl}, 5 \mathrm{KCl}, 1.2 \mathrm{~K}_{2} \mathrm{HPO}_{4}, 1.2 \mathrm{MgSO}_{4}, 1.2 \mathrm{CaCl}_{2}$, $25 \mathrm{NaHCO}_{3}$, and 10 glucose, and was continuously bubbled with a $95 \% \mathrm{O}_{2}-5 \% \mathrm{CO}_{2}$ gas mixture. All drugs were added to the perfusate. Aortic arch pressure was measured via a side port manometer, displayed on a chart recorder and recorded on FM magnetic tape. Aortic arch pressure was maintained at a constant non-pulsatile $80 \mathrm{mmHg}$ between tests.

\section{Single fiber BR pressure tests}

For single fiber studies, whole ADN nerves were split to fine filaments by successive micro-dissection using $30 \mathrm{G}$ disposable needles (Bectin Dickinson, Franklin, NJ). Those splits containing one or a few active fibers were placed on a pair of fine Pt-Ir electrodes that were connected to a high-gain differential preamplifier (PAR 113, Princeton E, G \& G). Unit discharge responses were recorded during slow ramp pressure tests $(<2 \mathrm{mmHg} / \mathrm{sec})$. For each test (control and drug trials), a series of three pressure ramps at five-minute intervals was applied to the arch and the full pressure response curve was recorded. For offline analysis, pressure was sampled at $100 \mathrm{~Hz}$ and the instantaneous spike frequency was calculated from pulses from a time-amplitude window discriminator (DIS-1, Bak Electronics, Mount Airy, MD) by a custom software program on a PC-based computer system. Final data analyses and comparisons focused on the third (15 min) trials for each condition.

\section{BR discharge properties - distinguishing types}

Short lengths that were split for single fiber recordings from ADN did not permit measurements of conduction velocity in these BR unit studies. However, several characteristics of the distribution of interspike intervals and the pressure-discharge relations distinguish two classes of discharge pattern, regular and irregular, that are associated with A- and C-type BRs, respectively [13,29,31,48-50]. Individual A-type BRs fire at highly regular interspike intervals whereas C-fiber BRs in contrast fire very irregularly [51]. Discharge frequency was calculated as the inverse of the interspike interval, that is the instantaneous discharge rate[14]. The variation in this instantaneous discharge frequency served as a key discriminating indicator between BR fiber types[13]. Variability in interspike interval was expressed as the coefficient of variation (COV) of the discharge intervals for each BR unit and calculated as the ratio of the standard deviation of the discharge rate divided by the mean discharge rate. The COV was calculated from segments of the control pressure-discharge relations over a fixed range of $10 \mathrm{~mm} \mathrm{Hg}$ (from 140 to 150 $\mathrm{mmHg}$ ) during the pressure ramp. For most units, these pressures were within the plateau range of pressures at near maximum discharge frequency. This COV index was used to distinguish regularly from irregularly discharging BRs.

\section{Analysis - pressure-discharge curves}

To characterize BR pressure-discharge relations, instantaneous frequency was plotted versus mean arterial pressure (OriginLabs, Origin 7.5, Northampton, MA) and characteristic discharge parameters were derived from the plots for each unit. A-type BRs exhibited a sharp jump from zero to a set frequency of regular discharge once they exceeded an adequate activation pressure, the threshold pressure (Pth) $[13,18]$. When averaged over the first ten points, that frequency of discharge at threshold (Fth) was highly consistent across repeated trials over time. The pressure-frequency relation above Pth was highly linear. The slope of the relation defined the suprathreshold pressure sensitivity (Sth or gain) and could be measured by fitting with a linear regression $\left(\mathrm{r}^{2}>0.9\right)$ over an interval of 20-40 $\mathrm{mmHg}$ before reaching a plateau of maximum discharge frequency (Fmax, calculated as an average frequency across $20 \mathrm{mmHg}$ and 200-250 spikes). C-type 
BRs, in contrast, have generally higher Pth and lower Fth, Fmax, and Sth as well as higher COV. Characteristic discharge parameters (Pth, Fth, Sth, and Fmax) were derived from the plots for each unit. Parameters from the $15 \mathrm{~min}$ tests for each condition were compared to controls by analysis of variance. P-values less than 0.05 were considered to be significant.

\section{VRI agonists}

CAP was initially dissolved in DMSO and then mixed with PBS to a concentrated stock solution containing $300 \mu \mathrm{M}$ CAP. This CAP stock solution was diluted with PBS to the final concentrations perfused through the aortic arch lumen. Controls included trials with application of vehicle alone at the highest concentration employed $(0.1 \%$ DMSO). Dose response relations were difficult to obtain with CAP due to the slow time course of recovery and the likelihood of desensitization [33]. Since we were most interested in establishing whether BRs were sensitive to TRPV1 agonists, we tested BRs at a CAP concentration of $1 \mu \mathrm{M}$, a concentration chosen to be sufficient to saturate TRPV1 and yet still remain within the "selective" concentration range described by others [52]. Furthermore, to test this assumption, we extended the CAP concentration up to $100 \mu \mathrm{M}$ to test for "non-specific" CAP effects in some experiments. RTX was initially dissolved in a concentrated stock solution as a mixture of methyl alcohol $(<1 \%)$ and PBS containing $50 \mu \mathrm{M}$ RTX. This RTX stock solution was diluted with PBS to final test concentrations. Controls included trials with vehicle alone. We applied RTX over a concentration range from $1 \mathrm{nM}$ to $10 \mu \mathrm{M}$. RTX concentration of $1 \mathrm{nM}$ was presumed to be a saturating concentration for TRPV1 [53] and >1 nM were applied to test for possible "non-specific" RTX effects.

\section{Competing interests}

The author(s) declare that they have no competing interests.

\section{Authors' contributions}

PR and WF carried out the single fiber studies plus their analysis and participated in the drafting of the manuscript. MA conceived and designed the study and carried out the whole nerve recordings. MA analyzed the digital recordings as well as drafted the manuscript. All authors read and approved the final manuscript.

\section{Acknowledgements}

We would like to thank Neelwant S. Sandhu for assistance in the early analysis of this work and funding from the National Institutes of Health HL41119 (MCA).

\section{References}

I. Burnstock G: $\mathbf{P 2 X}$ receptors in sensory neurones. Br J Anaesth 2000, 84:476-488.

2. Foreman RD: Integration of viscerosomatic sensory input at the spinal level. Prog Brain Res 2000, I22:209-22I.
3. Lawson SN: Morphological and biochemical cell types of sensory neurons. In Sensory neurons: diversity, development, and plasticity Edited by: Scott SA. New York, Oxford University Press; 1992:27-59.

4. Li BY, Schild JH: Patch clamp electrophysiology in the nodose ganglia of the adult rat. J Neurosci Meth 2002, II 15:157-167.

5. Caterina MJ, Julius D: Sense and specificity: a molecular identity for nociceptors. Curr Opin Neurobiol 1999, 9:525-530.

6. Petruska JC, Napaporn J, Johnson RD, Cooper BY: Chemical responsiveness and histochemical phenotype of electrophysiologically classified cells of the adult rat dorsal root ganglion. Neuroscience 2002, I 15:15-30.

7. Ringkamp M, Peng YB, Wu G, Hartke TV, Campbell JN, Meyer RA: Capsaicin responses in heat-sensitive and heat-insensitive $A$ fiber nociceptors. J Neurosci 200I, 21 : 4460-4468.

8. Baumann TK, Simone DA, Shain CN, LaMotte RH: Neurogenic hyperalgesia: the search for the primary cutaneous afferent fibers that contribute to capsaicin-induced pain and hyperalgesia. J Neurophysiol 1991, 66:212-226.

9. Helliwell RJA, McLatchie LM, Clarke M, Winter J, Bevan S, Mclntyre $P$ : Capsaicin sensitivity is associated with the expression of the vanilloid (capsaicin) receptor (VRI) MRNA in adult rat sensory ganglia. Neurosci Lett 1998, 250:177-180.

10. Michl T, Jocic M, Heinemann A, Schuligoi R, Holzer P: Vagal afferent signaling of a gastric mucosal acid insult to medullary, pontine, thalamic, hypothalamic and limbic, but not cortical, nuclei of the rat brain. Pain 200I, 92:19-27.

II. Krauhs JM: Structure of rat aortic baroreceptors and their relationship to connective tissue. J Neurocytol I979, 8:40I-I4.

12. Doan TN, Stephans K, Ramirez AN, Glazebrook PA, Andresen MC, Kunze DL: Differential distribution and function of hyperpolarization-activated channels in sensory neurons and mechanosensitive fibers. J Neurosci 2004, 24:3335-3343.

13. Kunze DL, Andresen MC: Arterial baroreceptors: Excitation and modulation. In Reflex Control of the Circulation Edited by: Zucker IH and Gilmore JP. Boca Raton, CRC Press; 199I:I4I-I66.

14. Andresen MC, Brodwick M, Yang M: Contrasting actions of cocaine, local anaesthetic and tetrodotoxin on discharge properties of rat aortic baroreceptors. Journal of Physiology 1994, 477:309-319.

15. Fan $\mathrm{W}$, Andresen MC: Differential frequency-dependent reflex integration of myelinated and nonmyelinated rat aortic baroreceptors. Am J Physiol 1998, 275: $\mathrm{H} 632-\mathrm{H} 640$.

16. Andresen MC, Kuraoka S, Brown AM: Individual and combined actions of calcium, sodium and potassium ions on baroreceptors in the rat. Circ Res 1979, 45:757-763.

17. Reynolds PJ, Yang M, Andresen MC: Contribution of potassium channels to rat aortic baroreceptor discharge properties. Brain Res 1994, 665:।15-122.

18. Schild JH, Clark JW, Hay M, Mendelowitz D, Andresen MC, Kunze $D L$ : A- and C-type nodose sensory neurons: Model interpretations of dynamic discharge characteristics. I Neurophysiol 1994, $71: 2338-2358$.

19. Munch PA, Andresen MC, Brown AM: Rapid resetting of aortic baroreceptors in vitro. Am J Physiol 1983, 244:H672-H680.

20. Szallasi A, Blumberg PM: Vanilloid (Capsaicin) receptors and mechanisms. Pharmacol Rev 1999, 5 1:159-212.

21. Szallasi A, Blumberg PM: Vanilloid receptors: New insights enhance potential as a therapeutic target. Pain 1996, 68: 195-208.

22. Sapru HN, Krieger AJ: Carotid and aortic chemoreceptor function in the rat. J Appl Physiol I977, 42:344-348.

23. Sapru HN, Gonzalez E, Krieger AJ: Aortic nerve stimulation in the rat: Cardiovascular and respiratory responses. Brain Res Bull 1981, 6:393-398.

24. Fan W, Reynolds PJ, Andresen MC: Frequency characteristics of baroreflex responses to electrical stimulation of aortic depressor and carotid sinus nerves in rats. Am J Physiol 1996, 27I: $\mathrm{H} 22$ I 8-H2227.

25. Andresen MC, Krauhs JM, Brown AM: Relationship of aortic wall baroreceptor properties during development in normotensive and spontaneously hypertensive rats. Circ Res 1978, 43:728-738.

26. Fazan VP, Salgado HC, Barreira AA: Aortic depressor nerve unmyelinated fibers in spontaneously hypertensive rats. Am J Physiol Heart Circ Physiol 200I, 280(4):H I560-4. 
27. Jin YH, Bailey TW, Li BY, Schild JH, Andresen MC: Purinergic and vanilloid receptor activation releases glutamate from separate cranial afferent terminals. J Neurosci 2004, 24:4709-47I7.

28. Doyle MW, Bailey TW, Jin YH, Andresen MC: Vanilloid receptors presynaptically modulate visceral afferent synaptic transmission in nucleus tractus solitarius. I Neurosci 2002, 22:8222-8229.

29. Thoren PN, Saum WR, Brown AM: Characteristics of rat aortic baroreceptors with nonmedullated afferent nerve fibers. Circ Res 1977, 40:23I-237.

30. Thoren PN, Andresen MC, Brown AM: Resetting of aortic baroreceptors with non-myelinated afferent fibers in spontaneously hypertensive rats. Acta Physiol Scand 1983, 11 7:91-97.

31. Thoren PN, Andresen MC, Brown AM: Effects of changes in extracellular ionic concentrations on aortic baroreceptors with nonmyelinated afferent fibers. Circ Res 1982, 50:4I 3-4I8.

32. Holzer P: Neural injury, repair, and adaptation in the GI tract. II. The elusive action of capsaicin on the vagus nerve. $\mathrm{Am}$ Physiol 1998, 275:G8-I3.

33. Marsh SJ, Stansfeld CE, Brown DA, Davey R, McCarthy D: The mechanism of action of capsaicin on sensory c-type neurons and their axons in vitro. Neuroscience 1987, 23:275-289.

34. Andresen MC, Yang M, Nelson SH, Steinsland OS: Cocaine inhibits baroreflex control of blood pressure by actions at arteria baroreceptors. Am J Physiol 1990, 258: HI 244-HI249.

35. Yang M, Andresen MC: Peptidergic modulation of mechanotransduction in rat arterial baroreceptors. Circ Res 1990 66:804-8I3.

36. Chang KSK, Yang M, Andresen MC: Clinically relevant concentrations of bupivacaine inhibit rat aortic baroreceptors. Anesth Analg 1994, 78:50I-506.

37. Andresen MC, Kunze DL: Ionic sensitivity of baroreceptors. Circ Res 1987, 61:166-171.

38. Jin YH, Bailey TW, Doyle MW, Li BY, Chang KSK, Schild JH, Mendelowitz D, Andresen MC: Ketamine differentially blocks sensory afferent synaptic transmission in medial nucleus tractus solitarius (mNTS). Anesthesiology 2003, 98:121-132.

39. Lawson SN: Phenotype and function of somatic primary afferent nociceptive neurones with C-, Adelta- or Aalpha/betafibres. Exp Physiol 2002, 87:239-244.

40. Tominaga M, Caterina MJ, Malmberg AB, Rosen TA, Gilbert H, Skinner K, Raumann BE, Basbaum Al, Julius D: The cloned capsaicin receptor integrates multiple pain-producing stimuli. Neuron 1998, 21:531-543.

4I. Mendelowitz D, Yang M, Andresen MC, Kunze DL: Localization and retention in vitro of fluorescently labeled aortic baroreceptor terminals on neurons from the nucleus tractus solitarius. Brain Res 1992, 581:339-343.

42. Guo A, Vulchanova L, Wang J, Li X, Elde R: Immunocytochemical localization of the vanilloid receptor I (VRI): relationship to neuropeptides, the $\mathrm{P} 2 \mathrm{X} 3$ purinoceptor and IB4 binding sites. Eur J Neurosci 1999, I I:946-958.

43. Coleridge HM, Coleridge JCG, Dangel A, Kidd C, Luck J, Sleight P: Impulses in slowly conducting vagal fibers from afferent endings in the veins, atria, and arteries of dogs and cats. Circ Res 1973, 33:87-97.

44. Coleridge JC, Coleridge HM: Afferent vagal $\mathbf{C}$ fibre innervation of the lungs and airways and its functional significance. $R e v$ Physiol Biochem Pharmacol 1984, 99: I-I IO.

45. Dworkin BR, Filewich R, Miller N, Craigmyle N, Pickering T: Baroreceptor activation reduces reactivity to noxious stimulation: Implications for hypertension. Science 1979, 205: I299-130I.

46. Guasti L, Zanotta D, Mainardi LT, Petrozzino MR, Grimoldi P, Garganico D, Diolisi A, Gaudio G, Klersy C, Grandi AM, Simoni C, Cerutti S: Hypertension-related hypoalgesia, autonomic function and spontaneous baroreflex sensitivity. Auton Neurosci 2002, 99:127-133.

47. Saper CB: Pain as a visceral sensation. Prog Brain Res 2000, I 22:237-243.

48. Brown AM, Saum WR, Yasui S: Baroreceptor dynamics and their relationship to afferent fiber type and hypertension. Circ Res 1978, 42:694-702.

49. Seagard JL, Van Brederode JFM, Dean C, Hopp FA, Gallenberg LA, Kampine JP: Firing characteristics of single-fiber carotid sinus baroreceptors. Circ Res 1990, 66:1499-1509.
50. Coleridge HM, Coleridge JCG, Schultz HD: Characteristics of $\mathbf{C}$ fibre baroreceptors in the carotid sinus of dogs. Journal of Physiology 1987, 394:29I-3।3.

5I. Yao T, Thoren PN: Characteristics of brachiocephalic and carotid sinus baroreceptors with non-medullated afferents in rabbit. Acta Physiol Scand 1983, I 17:1-8.

52. Szallasi A, Goso C, Blumberg PM, Manzini S: Competitive inhibition by capsazepine of $[3 \mathrm{H}]$ resiniferatoxin binding of central (spinal cord and dorsal root ganglia) and peripheral (urinary bladder and airways) vanilloid (capsaicin) receptors in the rat. J Pharmacol Exp Ther 1993, 267:728-733.

53. Acs G, Palkovits M, Blumberg PM: Specific binding of [3H]resiniferatoxin by human and rat preoptic area, locus ceruleus, medial hypothalamus, reticular formation and ventral thalamus membrane preparations. Life Sciences 1996, 59:1899-1908.
Publish with Bio Med Central and every scientist can read your work free of charge

"BioMed Central will be the most significant development for disseminating the results of biomedical research in our lifetime. "

Sir Paul Nurse, Cancer Research UK

Your research papers will be:

- available free of charge to the entire biomedical community

- peer reviewed and published immediately upon acceptance

- cited in PubMed and archived on PubMed Central

- yours - you keep the copyright

Submit your manuscript here:

http://www.biomedcentral.com/info/publishing_adv.asp
Biomedcentral 